\title{
A low initial serum sodium level is associated with an increased risk of overcorrection in patients with chronic profound hyponatremia: a retrospective cohort analysis
}

Sae Aratani ${ }^{1,2^{*}}$, Masahiko Hara ${ }^{3}$, Masahiko Nagahama', Fumika Taki', Miyuki Futatsuyama', Shuichi Tsuruoka ${ }^{2}$ and Yasuhiro Komatsu ${ }^{1}$

\begin{abstract}
Background: Even with abundant evidence for osmotic demyelination in patients with hyponatremia, the risk factors for overcorrection have not been fully investigated. Therefore the purpose of this study is to clarify the risks for overcorrection during the treatment of chronic profound hyponatremia.

Methods: This is a single-center retrospective observational study. We enrolled 56 adult patients with a serum sodium ( $\mathrm{SNa}$ ) concentration of $\leq 125 \mathrm{mEq} / \mathrm{L}$ who were treated in an intensive care unit by nephrologists using a locally developed, fixed treatment algorithm between February 2012 and April 2014. The impact of patient parameters on the incidence of overcorrection was estimated using univariable and multivariable logistic regression models. Overcorrection was defined as an increase of SNa by $>10 \mathrm{mEq} / \mathrm{L}$ and $>18 \mathrm{mEq} / \mathrm{L}$ during the first 24 and 48 h, respectively.

Results: The median age was 78 years, $48.2 \%$ were male, and $94.6 \%$ of the patients presented with symptoms associated with hyponatremia. The initial median SNa was $115 \mathrm{mEq} / \mathrm{L}$ (quartile, $111-119 \mathrm{mEq} / \mathrm{L}$ ). A total of 11 (19.6\%) patients met the criteria for overcorrection with 9 (16.0\%) occurring at $24 \mathrm{~h}, 6(10.7 \%)$ at $48 \mathrm{~h}$, and 4 (7.1\%) at both 24 and $48 \mathrm{~h}$. However, none of these patients developed osmotic demyelination. Primary polydipsia, initial $\mathrm{SNa}$, and early urine output were the significant risk factors for overcorrection on univariable analysis. Multivariable analysis revealed that the initial SNa had a statistically significant impact on the incidence of overcorrection with an adjusted odds ratio of 0.84 (95\% confidence interval, $0.70-0.98 ; p=0.037$ ) for every $1 \mathrm{mEq} / \mathrm{L}$ increase. Additionaly, the increase in $\mathrm{SNa}$ during the first $4 \mathrm{~h}$ and early urine output were significantly higher in patients with overcorrection than in those without ( $p=0.001$ and 0.005 , respectively).
\end{abstract}

Conclusions: An initial low level of SNa was associated with an increased risk of overcorrection in patients with profound hyponatremia. In this regard, the rapid increase in SNa during the first $4 \mathrm{~h}$ may play an important role.

Keywords: Chronic profound hyponatremia, Overcorrection, Risk factor

\footnotetext{
*Correspondence: sae-aratani@nms.ac.jp

'Department of Nephrology, St. Luke's International Hospital, Tokyo, Japan

${ }^{2}$ Department of Nephrology, Graduate School of Medicine, Nippon Medical

School, 1-1-5 Sendagi, Bunkyo-ku, Tokyo 113-8603, Japan

Full list of author information is available at the end of the article
} 


\section{Background}

Hyponatremia, defined as a serum sodium ( $\mathrm{SNa}$ ) concentration of $<135 \mathrm{mEq} / \mathrm{L}$, is a water balance disorder, with a relative excess of body water in relation to sodium [1]. Some reports have classified SNa $\leq 125 \mathrm{mEq} / \mathrm{L}$ as "profound" hyponatremia [2, 3]. Since profound hyponatremia is also associated with fatal complications such as brain herniation, appropriate treatments for hyponatremia have been discussed intensively worldwide [4-6]. For example, urgent therapy using hypertonic saline is justified in life-threatening conditions caused by hyponatremia complicated with seizures and coma $[2,7,8]$. In contrast, the problem of overcorrection makes the treatment of hyponatremia difficult because it can provoke osmotic demyelination (ODS), which is a dreaded neurologic complication associated with high mortality [9]. Therefore, the international guidelines recommend limiting the increase of $\mathrm{SNa}$ to within $10 \mathrm{mEq} / \mathrm{L}$ and $18 \mathrm{mEq} / \mathrm{L}$ during the first 24 and $48 \mathrm{~h}$, respectively, from the initiation of treatment for hyponatremia [2, 7]. To achieve the ideal correction rate of hyponatremia, several strategies including administration of desmopressin acetate (DDAVP), 3\% hypertonic saline in combination with DDAVP, and re-lowering the SNa with 5\% dextrose in water (D5W) have been introduced [10-13]. However, there is a paucity of literature on the risk factors for overcorrection [14], especially in "Chronic" profound hyponatremia, which carries a greater risk of neurologic complications from overcorrection, even though several risk factors for ODS have been identified, including $\mathrm{SNa} \leq 105 \mathrm{mEq} / \mathrm{L}$ at presentation, overcorrection itself, malnutrition, hypokalemia, and liver disease [15-22]. We hypothesized that the identification of risk factors for overcorrection can improve the safety and efficacy of the treatment of chronic hyponatremia.

\section{Methods}

\section{Aims}

The aim of this study was to determine the risks for overcorrection during the treatment of chronic profound hyponatremia to provide physicians with additional information on the safe and ideal treatment of hyponatremia.

\section{Setting}

This was a single-center retrospective cohort study, conducted by reviewing the medical records of a 520-bed teaching hospital (St. Luke's International Hospital).

\section{Study patients}

Consecutive patients with chronic profound hyponatremia, who were attended to by nephrologists, and treated in an intensive care unit (ICU) between February 2012 and April 2014, were included. Chronic hyponatremia was defined as hyponatremia that was documented to exist $>48 \mathrm{~h}$. If the duration could not be identified, we considered it as chronic [2]. Among the 64 patients who were admitted to the ICU with Sna $\leq 125 \mathrm{mEq} / \mathrm{L}$, we excluded 8 who were not treated for hyponatremia by nephrologists. This exclusion ensured that treatment and data gathering were uniform throughout the study. Finally, 56 consecutive patients with $\mathrm{SNa} \leq 125 \mathrm{mEq} / \mathrm{L}$ were included in the present study. The number of patients was confirmed using the treatment list of our department, as well as the electrical patient records of the hospital.

\section{Treatment protocol for Hyponatremia}

All patients were treated using our standardized therapeutic protocol for hyponatremia (Fig. 1). This therapeutic protocol fundamentally complied with the international treatment recommendations on chronic profound hyponatremia [2, 8], although it did involve an exceptionally aggressive strategy to avoid undertreatment. The steps in this protocol are carried out in sequence, rather than simultaneously. First, all the patients were evaluated to identify the causes of hyponatremia. This evaluation involved (1) an interview about the history of the present illness, (2) vital signs, (3) physical examination, (4) laboratory data, and (5) echocardiography, if appropriate. Urine osmolality $\leqq 100 \mathrm{mOsm} / \mathrm{kg}$ suggested that the hyponatremia was caused by primary polydipsia or poor sodium intake. Patientsand received cause-specific treatments, such as water restriction for primary polydipsia, discontinuation of a drug that caused hyponatremia, and amelioration of physiological stimulation of antidiuretic hormone (ADH). In addition, if patients had severe symptoms, such as seizures, coma, or cardiorespiratory distress, an intravenous (i.v.) bolus infusion of $3 \%$ hypertonic saline of weight-based $(2 \mathrm{~mL} /$ $\mathrm{kg}$ ) amount was initiated until the symptoms improved. When the patients were relieved from these severe symptoms, they were assessed to determine the extracellular water (ECW) status. Patients were considered to have hypovolemic hyponatremia if the following findings were present, along with the discretion of the attending physician: history of gastrointestinal loss, reduced oral intake, thiazide usage, reduced turgor, or prolonged capillary refill time on physical examination, urine $\mathrm{Na} \leqq$ $30 \mathrm{mEq} / \mathrm{L}$, and collapsed IVC on echography. Hydration with $0.9 \%$ saline at $1 \mathrm{~mL} / \mathrm{kg} / \mathrm{h}$ i.v. was initiated for patients who were diagnosed with reduced ECW. The administration speed of $0.9 \%$ saline was increased to $2 \mathrm{~mL} /$ $\mathrm{kg} / \mathrm{h}$ when the patient could not take food orally.

Subsequently, we evaluated the $\mathrm{SNa}$ and urine sodium (UNa), urine potassium (UK), and urine output every 2$4 \mathrm{~h}$ during the first $48 \mathrm{~h}$. Note that our remarkable degree of monitoring was to ensure safer and uniform treatment throughout the study. 


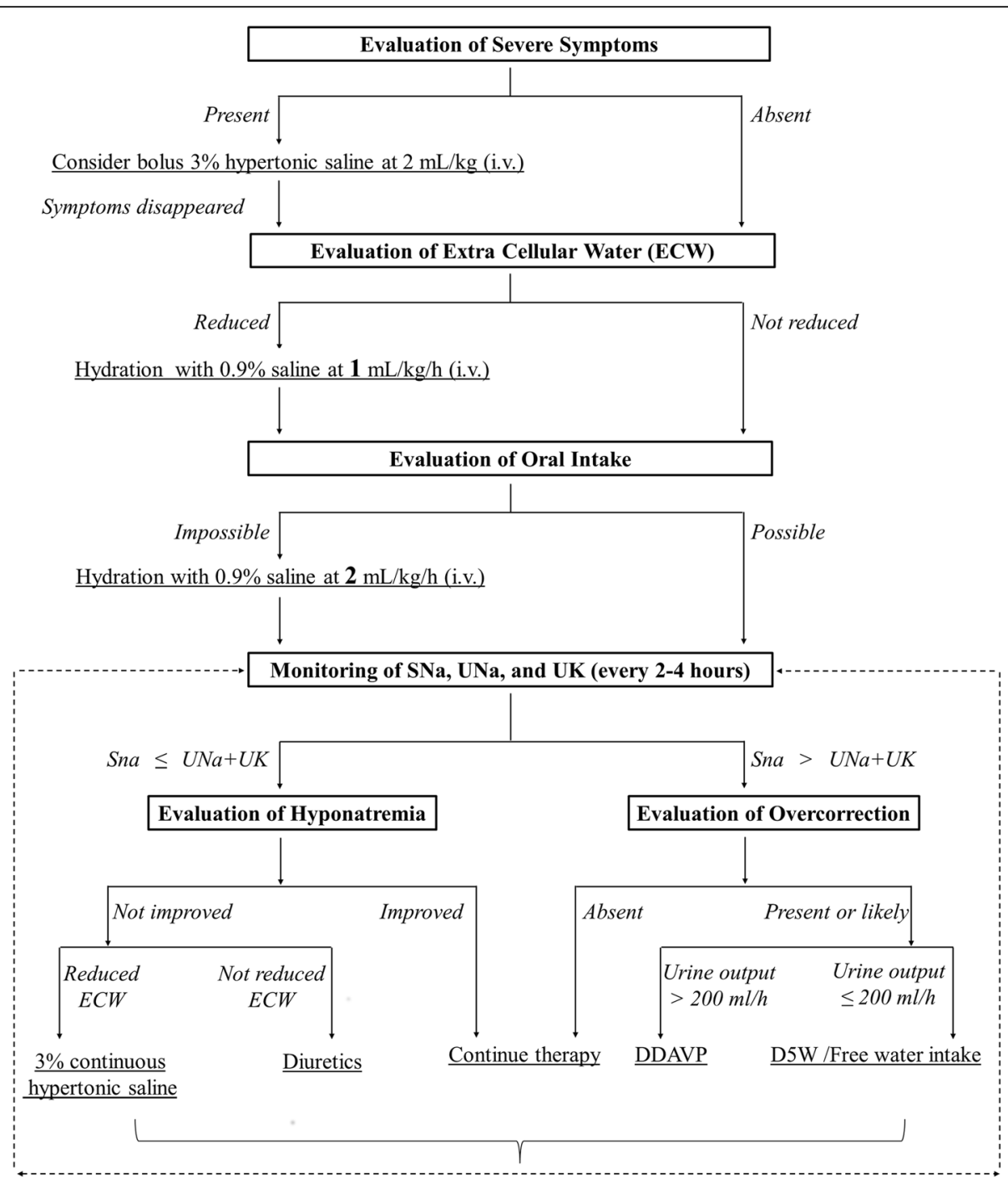

Fig. 1 Standardized Therapeutic Protocol of Hyponatremia at Our Institution. Details of the protocol was explained in the methods section. All the patients were evaluated to identify the causes of hyponatremia and received cause-specific treatments. Bolus infusion of $3 \%$ hypertonic saline was administered for patients with severe symptoms, until the symptoms improved. DDAVP, desmopressin; D5W, 5\% dextrose in water; ECW, extra cellular water; i.v., intravenous injection; p.o., per os; SNa, serum sodium; UK, urine potassium; and UNa, urine sodium

We defined the initial 4-h urine output as "early urine output." We compared the SNa to the total amount of $\mathrm{UNa}$ and $\mathrm{UK}(\mathrm{UNa}+\mathrm{UK})$ to predict the possibility of a subsequent spontaneous increase in the SNa. In case the $\mathrm{SNa}$ was $\leq \mathrm{UNa}+\mathrm{UK}$, hyponatremia was assumed not to be corrected spontaneously due to the absence of electrolyte-free water in the urine, and $3 \%$ hypertonic saline at a continuous rate of $0.5-1.0 \mathrm{~mL} / \mathrm{kg} / \mathrm{h}$ or diuretics were administered if hyponatremia persisted in the subsequent $4 \mathrm{~h}$. Thus, 3\% hypertonic saline was administered to patients with reduced ECW, and diuretics such as loop diuretics or tolvaptan were administered to patients without reduced ECW. Administration of 3\% hypertonic saline was continued at $0.5-1.0 \mathrm{~mL} / \mathrm{kg} / \mathrm{h}$ until the $\mathrm{SNa}$ improved. We used this relatively aggressive protocol to avoid under-treatment, based on evidence that even mild hyponatremia is associated with increased morbidity and mortality in both hospitalized and ambulatory patients [23, 24].

On the contrary, if the $\mathrm{SNa}$ was $>\mathrm{UNa}+\mathrm{UK}, \mathrm{SNa}$ was expected to increase spontaneously by free water diuresis as the urine contained electrolyte free water. In such a situation, there was a subsequent possibility of overcorrection. We defined overcorrection as an increase of $\mathrm{SNa}$ by $>10 \mathrm{mEq} / \mathrm{L}$ and $>18 \mathrm{mEq} / \mathrm{L}$ during the first 24 and $48 \mathrm{~h}$, respectively. Electrolyte-free water, D5W, or DDAVP was administered to prevent or manage the risk of overcorrection. DDAVP was administrated as an intranasal spray at a dose of $2.5-10 \mu \mathrm{g}$ in patients with urine output $>200 \mathrm{~mL} / \mathrm{h}$; urinary losses 
were replaced with D5W in patients with urine output $\leq 200 \mathrm{~mL} / \mathrm{h}$. If patients could consume free water orally, they were instructed to do so, instead of administering D5W infusion. We performed such interventions for patients who were likely to meet the criteria of overcorrection mentioned above as prophylactic interventions; those who met the criteria of overcorrection were administered these as therapeutic interventions.

\section{Statistical analysis}

We set the primary endpoint of the present study as overcorrection of $\mathrm{SNa}$, which was defined as an increase in the $\mathrm{SNa}$ by $>10 \mathrm{mEq} / \mathrm{L}$ and $>18 \mathrm{mEq} / \mathrm{L}$ during the first 24 and $48 \mathrm{~h}$, respectively $[2,7]$. Categorical data were represented as percentages (\%) and continuous data as medians (25-75 percentiles). The impact of patient parameters on the incidence of overcorrection was estimated using univariable and multivariable logistic regression models, and represented as odds ratios (OR) with $95 \%$ confidence intervals $(95 \% \mathrm{CI})$. In the multivariable model, the adjusted covariates included age, gender, presence of primary polydipsia, initial $\mathrm{SNa}$, initial creatinine, and early urine output, and continuous infusion of $3 \%$ hypertonic saline; these constituted multivariable model 1. We selected these variables based on their clinical perspectives as only 11 primary events were identified in the present study. We also created a multivariable logistic regression model including 3 variables that demonstrated a $P$ value of $<0.05$ in a univariable model; these constituted multivariable model 2. A P value $<0.05$ was considered statistically significant. For the comparison of patient parameters and treatment strategies, we divided our patients into 2 groups: the noovercorrection group $(n=45)$ and overcorrection group $(n=11)$. The chi-square test or Wilcoxon rank sum test was used for comparisons of categorical and continuous data between the groups, respectively. We conducted all statistical analyses using the $\mathrm{R}$ software package (version 3.3.01, R Development Core Team, https://www.r-project.org/).

\section{Results}

Table 1 shows the characteristics of the study population. The median age was 78 years; $48.2 \%$ were male. Most patients (94.6\%) were symptomatic and 3 (5.4\%) had severe symptoms. Among the 3 patients with severe symptoms, only one received a bolus infusion of $3 \%$ hypertonic saline, because the other 2 patients' symptoms had resolved by the time the nephrologists evaluated them. In contrast, 16 patients received 3\% hypertonic saline at a continuous rate (Table 3 ). There were multiple causes for hyponatremia; 36 (64.3\%) patients were diagnosed to have hypovolemic hyponatremia and 21 (37.5\%) with hyponatremia secondary to poor solute intake (Table 1). Table 2 shows the patients' laboratory data at presentation. The initial median $\mathrm{SNa}$ was $115 \mathrm{mEq} / \mathrm{L}$ (quartile, 111-119 $\mathrm{mEq} / \mathrm{L}$ ). Table 3 shows the treatments and outcomes after the nephrology consultation. Hydration with $0.9 \%$ saline for volume repletion was performed in $36(64.3 \%)$ patients, maintenance fluid infusion with $0.9 \%$ saline was performed in 32 (57.1\%) patients, and 3\% hypertonic saline was administered in 17 (30.4\%) patients. Loop diuretics (i.v.) were administered in $4(7.1 \%)$ patients and tolvaptan per os (p.o.) in 4 (7.1\%) patients. Prophylactic and therapeutic interventions for overcorrection included the use of D5W in 18 (32.1\%) patients, free water intake in $2(3.6 \%)$ patients, and DDAVP in $11(19.6 \%)$ patients. The mean initial time of DDAVP administration was $8 \mathrm{~h}$ (range, 7-12 h) after the presentation. A total of $11(19.6 \%)$ patients met the criteria for overcorrection: $9(16.0 \%)$ patients in $24 \mathrm{~h}, 6$ (10.7\%) in $48 \mathrm{~h}$, and $4(7.1 \%)$ in both 24 and $48 \mathrm{~h}$. Fortunately, none of the patients developed ODS during or after hyponatremia treatment in this study. Figure 2 shows the time course of $\mathrm{SNa}$ levels during the first $48 \mathrm{~h}$ after the treatment.

Regarding the risk of overcorrection, Table 4 shows that primary polydipsia, initial $\mathrm{SNa}$ at presentation, and early urine output were significant risk factors on the univariable analysis. In addition, multivariable model 1 and 2 revealed that only the initial $\mathrm{SNa}$ at presentation had a statistically significant impact on the incidence of overcorrection with an adjusted OR of 0.84 (95\% CI, 0.70-0.98; $p=0.037$ ) for every $1 \mathrm{mEq} / \mathrm{L}$ increase in the multivariable model 1 after adjustment of all covariates listed in Table 3. Finally, we divided our study patients into the overcorrection and no-overcorrection groups, and compared the patient parameters, information on treatments and outcomes in Table 1, and the trend of SNa in Fig. 2 just for reference. It was noted that the increase in $\mathrm{SNa}$ during the first $4 \mathrm{~h}$ and early urine output were significantly higher for patients in the overcorrection group, as shown in Table 1 ( $p=0.001$ and 0.005 , respectively).

In addition, among the 56 patients, 6 (11\%) from the "no-overcorrection" group died during hospitalization due to infectious disease $(n=4)$ or cancer $(n=2)$. Both of these conditions may have caused hyponatremia in these patients. Among the 50 patients who were discharged alive, 12 were lost to follow-up partly because they were referred to their family doctors or because they cancelled their outpatient visits unexpectedly. Among the 38 patients who were ultimately followed-up at our institution, there were no re-hospitalizations due to hyponatremia within a median follow-up of 822 (quartile, 1991411) days. 
Table 1 Patient characteristics

\begin{tabular}{|c|c|c|c|c|c|}
\hline Parameters & Missing & $\begin{array}{l}\text { Total } \\
(n=56)\end{array}$ & $\begin{array}{l}\text { No-Overcorrection } \\
(n=45)\end{array}$ & $\begin{array}{l}\text { Overcorrection } \\
(n=11)\end{array}$ & $p$-value \\
\hline Age, years old & 0 & $78(60-83)$ & $79(63-84)$ & $60(48-82)$ & 0.129 \\
\hline Male & 0 & $27(48.2)$ & $22(48.9)$ & $5(45.5)$ & 0.838 \\
\hline Body weight, kg & 0 & $52(42-60)$ & $50(40-58)$ & $56(51-69)$ & 0.049 \\
\hline \multicolumn{6}{|l|}{ Symptoms } \\
\hline \multicolumn{6}{|l|}{ Severe symptoms } \\
\hline Seizures & 0 & $3(5.4)$ & $0(0.0)$ & $3(27.3)$ & $<0.001$ \\
\hline Coma & 0 & $0(0.0)$ & $0(0.0)$ & $0(0.0)$ & - \\
\hline Cardiorespiratory distress & 0 & $0(0.0)$ & $0(0.0)$ & $0(0.0)$ & - \\
\hline \multicolumn{6}{|l|}{ Other symptoms } \\
\hline Vomit & 0 & $13(23.2)$ & $9(20.0)$ & $4(36.4)$ & 0.249 \\
\hline Nausea & 0 & $9(16.1)$ & $7(15.6)$ & $2(18.2)$ & 0.832 \\
\hline Loss of appetite & 0 & $10(17.9)$ & $10(22.2)$ & $0(0.0)$ & 0.085 \\
\hline Disorientation & 0 & $34(60.7)$ & $28(62.2)$ & $6(54.5)$ & 0.640 \\
\hline Impairment of gait or fall & 0 & $10(17.9)$ & $9(20.0)$ & $1(9.1)$ & 0.397 \\
\hline General fatigue & 0 & $3(5.4)$ & $3(6.7)$ & $0(0.0)$ & 0.379 \\
\hline Asymptomatic & 0 & $3(5.4)$ & $2(4.4)$ & $1(9.1)$ & 0.540 \\
\hline \multicolumn{6}{|l|}{ Cause of hyponatremia } \\
\hline Primary polydipsia & 0 & $6(10.7)$ & $2(4.4)$ & $4(36.4)$ & 0.002 \\
\hline Poor solute intake & 0 & $21(37.5)$ & $17(37.8)$ & $4(36.4)$ & 0.931 \\
\hline Hypovolemic hyponatremia & 0 & $36(64.3)$ & $30(66.7)$ & $6(54.5)$ & 0.452 \\
\hline SIADH & 0 & $4(7.1)$ & $4(8.9)$ & $0(0.0)$ & 0.305 \\
\hline Physiological stimulation of ADH & 0 & $11(19.6)$ & $9(20.0)$ & $2(18.2)$ & 0.892 \\
\hline CSW & 0 & $2(3.6)$ & $2(4.4)$ & $0(0.0)$ & 0.476 \\
\hline Drug intoxication & 0 & $10(17.9)$ & $8(17.8)$ & $2(18.2)$ & 0.975 \\
\hline Unidentified & 0 & $1(1.8)$ & $1(2.2)$ & $0(0.0)$ & 0.618 \\
\hline \multicolumn{6}{|l|}{ Underlying disease } \\
\hline Psychiatric disease & 0 & $6(10.7)$ & $3(6.7)$ & $3(27.3)$ & 0.048 \\
\hline Schizophrenia & 0 & $1(1.8)$ & $0(0.0)$ & $1(9.1)$ & 0.041 \\
\hline Anorexia nervosa & 0 & $1(1.8)$ & $1(2.2)$ & $0(0.0)$ & 0.618 \\
\hline Depression & 0 & $3(5.4)$ & $2(4.4)$ & $1(9.1)$ & 0.540 \\
\hline Development disorder & 0 & $1(1.8)$ & $0(0.0)$ & $1(9.1)$ & 0.041 \\
\hline Infectious disease & 0 & $14(25.0)$ & $13(28.9)$ & $1(9.1)$ & 0.174 \\
\hline Urinary tract infection & 0 & $5(8.9)$ & $4(8.9)$ & $1(9.1)$ & 0.983 \\
\hline Pneumonia & 0 & $3(5.4)$ & $3(6.7)$ & $0(0.0)$ & 0.379 \\
\hline Thoracic empyema & 0 & $1(1.8)$ & $1(2.2)$ & $0(0.0)$ & 0.618 \\
\hline Meningitis & 0 & 2 (3.6) & $2(4.4)$ & $0(0.0)$ & 0.476 \\
\hline Influenza & 0 & $2(3.6)$ & $2(4.4)$ & $0(0.0)$ & 0.476 \\
\hline Cellulitis & 0 & $2(3.6)$ & $2(4.4)$ & $0(0.0)$ & 0.476 \\
\hline HIV & 0 & $1(1.8)$ & $1(2.2)$ & $0(0.0)$ & 0.618 \\
\hline Malignant disease & 0 & $6(10.7)$ & $5(11.1)$ & $1(9.1)$ & 0.846 \\
\hline Stomach & 0 & $1(1.8)$ & $1(2.2)$ & $0(0.0)$ & 0.618 \\
\hline Pancreatic & 0 & $2(3.6)$ & $2(4.4)$ & $0(0.0)$ & 0.476 \\
\hline Renal & 0 & $1(1.8)$ & $1(2.2)$ & $0(0.0)$ & 0.618 \\
\hline
\end{tabular}


Table 1 Patient characteristics (Continued)

\begin{tabular}{|c|c|c|c|c|c|}
\hline Parameters & Missing & $\begin{array}{l}\text { Total } \\
(n=56)\end{array}$ & $\begin{array}{l}\text { No-Overcorrection } \\
(n=45)\end{array}$ & $\begin{array}{l}\text { Overcorrection } \\
(n=11)\end{array}$ & $p$-value \\
\hline Prostatic & & $2(3.6)$ & $1(2.2)$ & $1(9.1)$ & 0.271 \\
\hline Alcohol abuse & 0 & $4(7.1)$ & $3(6.7)$ & $1(9.1)$ & 0.780 \\
\hline Unidentified & 0 & $28(50.0)$ & $23(51.1)$ & $5(45.5)$ & 0.737 \\
\hline \multicolumn{6}{|c|}{ Medication on admission } \\
\hline Thiazide & 0 & $7(12.5)$ & $5(11.1)$ & $2(18.2)$ & 0.525 \\
\hline Antipsychotic drug & 0 & $2(3.6)$ & $2(4.4)$ & $0(0.0)$ & 0.476 \\
\hline DDAVP & 0 & $2(3.6)$ & $2(4.4)$ & $0(0.0)$ & 0.476 \\
\hline
\end{tabular}

$A D H$ antidiuretic hormone, CSW cerebral salt wasting, DDAVP desmopressin, HIV human immunodeficiency virus, and SIADH syndrome of inappropriate antidiuretic hormone

Categorical variables are shown as numbers (percentages) and continuous variables as medians (25-75 percentiles)

\section{Discussion}

In this single-center retrospective observational study, we investigated the risk factors for overcorrection by enrolling 56 patients with chronic profound hyponatremia who underwent standardized therapeutic strategies including DDAVP administration at our institution. We found two clinically important observations. First, an initial low level of $\mathrm{SNa}$ was a statistically significant risk factor for overcorrection. Second, the rapid increase in the first $4 \mathrm{~h}$ of the treatment might be responsible for the overcorrection, as suggested by Fig. 2 .
Incidence of overcorrection and ODS

The incidence of overcorrection varies depending on its definition and mode of correction [2, 7]. A retrospective study that involved 412 patients with $\mathrm{SNa}<120 \mathrm{mEq} / \mathrm{L}$, in which overcorrection was defined as an increase in the $\mathrm{SNa}$ by $>10 \mathrm{mEq} / \mathrm{L}$ during the first $24 \mathrm{~h}$, reported that $114(27.9 \%)$ patients were overcorrected [19]. The study, however, did not discuss the treatment strategies for hyponatremia in detail. Another retrospective study that included 62 patients concluded that 7 (11.3\%) patients exceeded the increase of $\mathrm{SNa}$ by $>12 \mathrm{mEq} / \mathrm{L}$ and 6 (9.7\%) patients by $18 \mathrm{mEq} / \mathrm{L}$ during the first 24 and

Table 2 Laboratory data at presentation

\begin{tabular}{|c|c|c|c|c|c|}
\hline Parameters & Missing & $\begin{array}{l}\text { Total } \\
(n=56)\end{array}$ & $\begin{array}{l}\text { No-Overcorrection } \\
(n=45)\end{array}$ & $\begin{array}{l}\text { Overcorrection } \\
(n=11)\end{array}$ & $p$-value \\
\hline \multicolumn{6}{|l|}{ Blood pressure, $\mathrm{mmHg}$} \\
\hline Systolic & 0 & $130(112-152)$ & $127(111-148)$ & $142(140-162)$ & 0.034 \\
\hline Diastolic & 0 & $70(62-83)$ & $70(60-82)$ & $78(72-89)$ & 0.137 \\
\hline \multicolumn{6}{|l|}{ Laboratory data } \\
\hline \multicolumn{6}{|l|}{ Blood analysis } \\
\hline Serum $\mathrm{Na}, \mathrm{mEq} / \mathrm{L}$ & 0 & $115(111-119)$ & $116(111-119)$ & $107(104-113)$ & 0.012 \\
\hline Serum $\mathrm{K}, \mathrm{mEq} / \mathrm{L}$ & 0 & $4.0(3.4-4.5)$ & $4.0(3.7-4.7)$ & $3.6(3.3-4.1)$ & 0.112 \\
\hline Serum BUN, mg/dL & 0 & $12.5(9.7-18.2)$ & $14.2(10.1-22.9)$ & $10.1(7.7-10.8)$ & 0.023 \\
\hline Serum $\mathrm{Cr}, \mathrm{mg} / \mathrm{dL}$ & 0 & $\begin{array}{l}0.65 \\
(0.44-0.94)\end{array}$ & $\begin{array}{l}0.66 \\
(0.46-1.12)\end{array}$ & $\begin{array}{l}0.47 \\
(0.42-0.73)\end{array}$ & 0.270 \\
\hline Serum TP, mg/dL & 6 & $6.4(6.0-7.3)$ & $6.4(6.0-7.3)$ & $7.3(6.3-7.8)$ & 0.260 \\
\hline Serum Glu, mg/dL & 8 & $123(98-144)$ & $124(94-144)$ & $120(115-138)$ & 0.741 \\
\hline Urinary analysis & 0 & & & & \\
\hline Urine $\mathrm{Na}, \mathrm{mEq} / \mathrm{L}$ & 0 & $41(20-65)$ & $41(24-66)$ & $33(17-46)$ & 0.343 \\
\hline Urine $\mathrm{K}, \mathrm{mEq} / \mathrm{L}$ & 0 & $28(14-44)$ & $33(17-44)$ & $13(10-31)$ & 0.058 \\
\hline Urine $\mathrm{Na}+\mathrm{K}, \mathrm{mEq} / \mathrm{L}$ & 0 & $74(49-114)$ & $75(52-115)$ & $57(28-97)$ & 0.101 \\
\hline Urine Osm, mOsm/kg $\mathrm{H}_{2} \mathrm{O}$ & 1 & $\begin{array}{l}332 \\
(245-493)\end{array}$ & $\begin{array}{l}336 \\
(265-502)\end{array}$ & $\begin{array}{l}217 \\
(137-359)\end{array}$ & 0.029 \\
\hline
\end{tabular}

BUN blood urea nitrogen, $\mathrm{Cr}$ creatinine, Glu glucose, $\mathrm{K}$ potassium, $\mathrm{Na}$ sodium, Osm osmolality, and $\mathrm{TP}$ total protein Continuous variables as medians (25-75 percentiles) 
Table 3 Treatments and outcomes

\begin{tabular}{|c|c|c|c|c|c|}
\hline Parameters & Missing & $\begin{array}{l}\text { Total } \\
(n=56)\end{array}$ & $\begin{array}{l}\text { No-overcorrection } \\
(n=45)\end{array}$ & $\begin{array}{l}\text { Overcorrection } \\
(n=11)\end{array}$ & $p$-value \\
\hline \multicolumn{6}{|l|}{ Treatment of hyponatremia } \\
\hline Hydration (0.9\% saline) & 0 & $36(64.3)$ & $30(66.7)$ & $6(54.5)$ & 0.452 \\
\hline Maintenance infusion (0.9\% saline) & 0 & $32(57.1)$ & $26(57.8)$ & $6(54.5)$ & 0.846 \\
\hline \multicolumn{6}{|l|}{$3 \%$ hypertonic saline } \\
\hline Bolus infusion & 0 & $1(1.8)$ & $0(0)$ & $1(9.1)$ & 0.041 \\
\hline Continuous infusion & 0 & $16(28.6)$ & $15(33.3)$ & $1(9.1)$ & 0.111 \\
\hline \multicolumn{6}{|l|}{ Diuretics } \\
\hline Loop diuretic (i.v.) & 0 & $4(7.1)$ & $4(8.9)$ & $0(0.0)$ & 0.305 \\
\hline Tolvaptan (p.o.) & 0 & $4(7.1)$ & $3(6.7)$ & $1(9.1)$ & 0.780 \\
\hline \multicolumn{6}{|l|}{ Intervention for overcorrection } \\
\hline D5W & 0 & $18(32.1)$ & $12(26.7)$ & $6(54.5)$ & 0.076 \\
\hline Instructed to free water intake & 0 & $2(3.6)$ & $1(2.2)$ & $1(9.1)$ & 0.271 \\
\hline DDAVP & 0 & $11(19.6)$ & $5(11.1)$ & $6(54.5)$ & 0.001 \\
\hline Time from admission, hours & 0 & $8(7-12)$ & $9(8-9)$ & $8(7-13)$ & 0.853 \\
\hline \multicolumn{6}{|l|}{ Outcomes } \\
\hline Osmotic demyelination & 0 & $0(0.0)$ & $0(0.0)$ & $0(0.0)$ & NA \\
\hline \multicolumn{6}{|l|}{ Increase of serum $\mathrm{Na}, \mathrm{mEq} / \mathrm{L}$} \\
\hline At $4 \mathrm{~h}$ & 5 & $2.0(1.0-4.0)$ & $2.0(0.0-3.0)$ & $6.5(3.3-8.5)$ & 0.001 \\
\hline At $24 \mathrm{~h}$ & 0 & $8(6-10)$ & $7(5-9)$ & $12(11-15)$ & $<0.001$ \\
\hline At $48 \mathrm{~h}$ & 5 & $14(12-17)$ & $13(11-15)$ & $19(17-23)$ & $<0.001$ \\
\hline Early urine output, mL/h & 0 & $\begin{array}{l}205 \\
(114-386)\end{array}$ & $\begin{array}{l}183 \\
(85-303)\end{array}$ & $\begin{array}{l}436 \\
(196-998)\end{array}$ & 0.005 \\
\hline Urine output at $24 \mathrm{~h}, \mathrm{~mL}$ & 0 & $\begin{array}{l}2008 \\
(1115-3101)\end{array}$ & $\begin{array}{l}1640 \\
(855-3005)\end{array}$ & $\begin{array}{l}3725 \\
(2229-4686)\end{array}$ & 0.001 \\
\hline Urine output at $48 \mathrm{~h}, \mathrm{~mL}$ & 0 & $\begin{array}{l}1930 \\
(1416-3006)\end{array}$ & $\begin{array}{l}1875 \\
(1315-2655)\end{array}$ & $\begin{array}{l}2695 \\
(1723-3750)\end{array}$ & 0.073 \\
\hline
\end{tabular}

DDAVP desmopressin, D5W 5\% dextrose in water, i.v. intravenous injection Na sodium, and p.o. per os

Categorical variables are shown as numbers (percentages) and continuous variables as medians (25-75 percentiles)

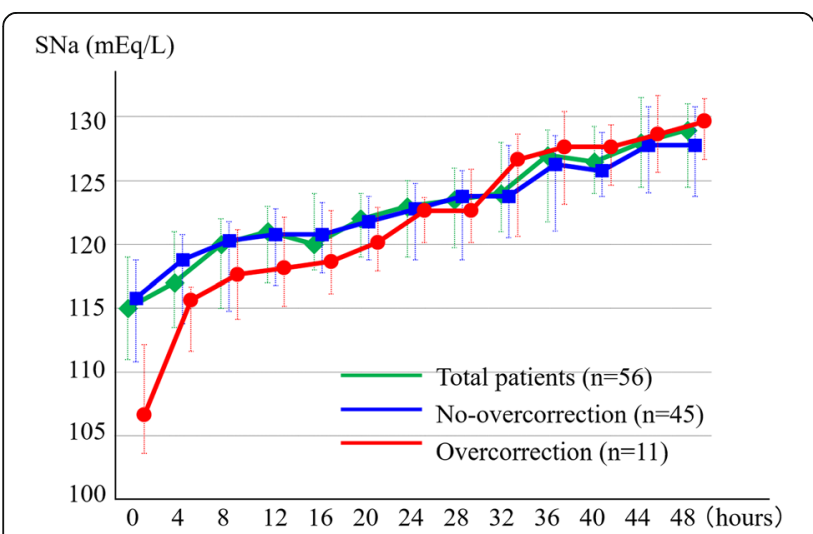

Fig. 2 The result of SNa during the first $48 \mathrm{~h}$. The results of SNa during the first $48 \mathrm{~h}$ are shown as medians (25-75 percentiles). The green line represents all patients, the blue line patients without overcorrection, and the red line patients with overcorrection. Error bars indicate the interquartile ranges. $\mathrm{SNa}$, serum sodium
$48 \mathrm{~h}$, respectively [14]. The treatment included administration of $3 \%$ hypertonic saline, D5W, and DDAVP, which were used in patients in whom overcorrection was likely or had occurred. The incidence of overcorrection in our study was consistent with that observed in these previous studies. We identified that 9 (16.0\%) patients had an increase in the $\mathrm{SNa}$ by $>10 \mathrm{mEq} / \mathrm{L}$ and $6(10.7 \%)$ by $>18 \mathrm{mEq} / \mathrm{L}$ during the first 24 and $48 \mathrm{~h}$, respectively.

The international guidelines define overcorrection with a safety margin. We speculated that no ODS occurred mainly because the increase in $\mathrm{SNa}$ was relatively limited in the present study; even in patients with overcorrection, $\mathrm{SNa}$ increased by $12 \mathrm{mEq} / \mathrm{L}$ (quartile, 11-15 mEq/L) and $19 \mathrm{mEq} / \mathrm{L}$ (quartile, $17-23 \mathrm{mEq} / \mathrm{L}$ ) during the first 24 and $48 \mathrm{~h}$, respectively (Table 3). Similarly, in a previous retrospective study in which four of 37 patients (11\%) with overcorrection developed ODS [25], the increases in $\mathrm{SNa}$ were $21 \pm 5 \mathrm{mEq} / \mathrm{L}$ and 
Table 4 Impact of each variable on overcorrection

\begin{tabular}{|c|c|c|c|c|c|c|}
\hline \multirow[b]{2}{*}{ Parameters } & \multicolumn{2}{|l|}{ Univariable } & \multicolumn{2}{|l|}{ Multivariable model 1} & \multicolumn{2}{|l|}{ Multivariable model 2} \\
\hline & OR $(95 \% \mathrm{Cl})$ & $p$-value & adjusted OR (95\% Cl) & $\overline{p \text {-value }}$ & adjusted OR (95\% Cl) & $p$-value \\
\hline Age & $0.97(0.93-1.01)$ & 0.108 & $0.98(0.92-1.05)$ & 0.537 & - & - \\
\hline Male & $0.87(0.22-3.30)$ & 0.838 & $0.63(1.00-3.56)$ & 0.603 & - & - \\
\hline Primary Polydipsia & $12.3(2.02-102.00)$ & 0.009 & $2.41(0.09-60.20)$ & 0.576 & $3.25(0.16-73.04)$ & 0.432 \\
\hline Serum $\mathrm{Na}$ & $0.83(0.71-0.94)$ & 0.006 & $0.84(0.70-0.98)$ & 0.036 & $0.86(0.73-0.99)$ & 0.041 \\
\hline Serum $\mathrm{Cr}$ & $1.12(0.51-2.04)$ & 0.722 & $1.61(0.72-4.01)$ & 0.218 & - & - \\
\hline Early urine output ${ }^{a}$ & $1.41(1.13-1.87)$ & 0.006 & $1.30(0.94-1.94)$ & 0.149 & $1.26(0.93-1.79)$ & 0.163 \\
\hline $3 \%$ hypertonic continuous infusion & $0.20(0.01-1.19)$ & 0.142 & $0.54(0.02-5.50)$ & 0.629 & - & - \\
\hline
\end{tabular}

$\mathrm{Cl}$ confidence interval $\mathrm{Cr}$ creatinine, $\mathrm{Na}$ sodium, and $\mathrm{OR}$ odds ratio

Multivariable model 1 included all 7 variables shown in the Table. Multivariable model 2 included 3 variables that showed statistical significance on univariable analysis

${ }^{a}$ Odds ratio per $100 \mathrm{~mL}$ increase

$28 \pm 8 \mathrm{mEq} / \mathrm{L}$ during the first 24 and $48 \mathrm{~h}$, respectively. Therefore, we believe that minimizing $\mathrm{SNa}$ increases is essential to prevent ODS, even when overcorrection does occur.

\section{Risk of overcorrection}

Risk factors for ODS included an initial $\mathrm{SNa}$ of $<105 \mathrm{mEq} / \mathrm{L}$ and overcorrection. International guidelines recommend avoidance of overcorrection in the management of patients with hyponatremia; however, risk factors for overcorrection have not been fully investigated $[2,7]$. In contrast, avoidance of overcorrection or ODS may lead to prolonged or inadequate management of patients with hyponatremia, leading to undercorrection in clinical practice. We need to develop an optimal treatment strategy to assure a safe correction rate of $\mathrm{SNa}$ to achieve an appropriate correction while avoiding overcorrection. With this point of view, we conducted this retrospective study to determine the risk factors for overcorrection and believe that our results will guide physicians in the management of these patients. Our study revealed that a low level of $\mathrm{SNa}$ at presentation was associated with overcorrection, with an adjusted OR of 1.19 for every $1 \mathrm{mEq} / \mathrm{L}$ decrease $(0.84$ for every $1 \mathrm{mEq} / \mathrm{L}$ increase). This meant that a $4 \mathrm{mEq} / \mathrm{L}$ lower $\mathrm{SNa}$ level doubled the risk of overcorrection. Although several previous retrospective studies have indicated that the $\mathrm{SNa}$ at presentation was lower in patients with overcorrection compared to those without, a direct association between the $\mathrm{SNa}$ levels and risk of overcorrection has not been evaluated previously [14]. Our results alert clinicians to be cautious of the incremental risk of overcorrection when patients present with low $\mathrm{SNa}$ levels.

\section{Mechanism and intervention of overcorrection}

Regarding the mechanism of overcorrection, it is noteworthy that a rapid increase in the $\mathrm{SNa}$ levels during the first $4 \mathrm{~h}$ of treatment might be responsible for the overcorrection, as suggested in Fig. 2. In our study, patients with overcorrection showed a rapid increase in the $\mathrm{SNa}$ levels soon after hospitalization, with greater early urine output, compared to those without overcorrection. This could happen when factors stimulating $\mathrm{ADH}$ secretion subside following hospitalization [26]. For example, resolution of hypovolemia by administration of $0.9 \%$ saline, discontinuation of thiazides, and amelioration of pain or stress would easily suppress the release of $\mathrm{ADH}[27,28]$, leading to free water diuresis. Thus, we speculated that the hospitalization itself strongly contributed to the suppression of ADH secretion and the resultant rapid increase in $\mathrm{SNa}$, especially when the $\mathrm{SNa}$ levels were very low. Hence, it is clinically important to manage the risk of overcorrection during the early period following presentation to avoid a rapid increase in the $\mathrm{SNa}$ levels; this should be considered even if a reactive approach, such as the one described in our standardized therapeutic protocol (Fig. 1), is followed. Sood L et al. recently proposed a unique approach to control the correction rate of hyponatremia by administering DDAVP as the initial treatment along with 3\% saline. Their study enrolled 25 patients and showed that the approach was an effective and safe strategy to manage water diuresis [10]. In that study, the mean increase in $\mathrm{SNa}$ was $5.8 \pm 2.8 \mathrm{mEq} / \mathrm{L}$ and $4.5 \pm 2.2 \mathrm{mEq} / \mathrm{L}$ during the first and second $24 \mathrm{~h}$, respectively. No patient experienced overcorrection. On the contrary, in our study, $54.5 \%$ of patients in the overcorrection group received DDAVP administration and the mean time from admission to DDAVP administration was $8 \mathrm{~h}$ (range, 7-13 h) (Table 2). Our results indicate that early detection and cautious monitoring of the rapid increase in $\mathrm{SNa}$ during the first $4 \mathrm{~h}$ of treatment are important in terms of clinical implications, although there is no consensus on the optimum monitoring frequency. For example, hourly monitoring or early administration of DDAVP during the first $4 \mathrm{~h}$ 
could be a reasonable and effective strategy to prevent overcorrection in high risk patients with an initial $\mathrm{SNa}$ of $<110 \mathrm{mEq} / \mathrm{L}$.

\section{Study limitations}

This study had some limitations. First, this was a singlecenter retrospective study with a small sample size of 56 patients. Some patients with chronic profound hyponatremia may have been admitted to the general ward and treated by general physicians, without the involvement of nephrologists. Second, the definition of overcorrection varies among studies [29]. Finally, we ourselves designed the algorithm used in hyponatremia treatment. The protocol basically complied with international guideline recommendations for the treatment of chronic profound hyponatremia, although we did employ an exceptionally aggressive strategy involving continuous administration of $3 \%$ hypertonic saline in some situations to avoid undertreatment $[2,8,23,24]$. In addition, the purpose of this standardized algorithm was not to recommend our treatment protocol to other institutions, but to make our results comparable to other studies. The appropriateness of applying diagnostic algorithms to treat hyponatremia remains to be studied, and physiology-based treatment must always be kept in mind [30,31]. Our data should be interpreted in the light of these limitations.

\section{Conclusions}

The present study identified that an initial low level of $\mathrm{SNa}$ was associated with an increased risk of overcorrection in patients with profound hyponatremia. The rapid increase in $\mathrm{SNa}$ during the first $4 \mathrm{~h}$ may play an important role in overcorrection. It is also important to note that no ODS occurred in the present study, and that minimizing $\mathrm{SNa}$ increases is important to prevent ODS, even when overcorrection does occur.

\section{Abbreviations \\ $\mathrm{ADH}$ : Antidiuretic hormone; BUN: Blood urea nitrogen; Cl: Confidence intervals; Cr: Creatinine; CSW: Cerebral salt wasting; D5W: 5\% dextrose in water; DDAVP: Desmopressin; ECW: Extracellular water; Glu: Glucose; HIV: Human immunodeficiency virus; i.v.: Intravenous injection; ICU: Intensive care unit; K: Potassium; Na: Sodium; ODS: Osmotic demyelination; OR: Odds ratios; Osm: Osmolality; p.o.: Per OS; SIADH: Syndrome of inappropriate antidiuretic hormone; TP: Total protein; UK: Urine potassium; UNa: Urine sodium}

\section{Acknowledgements}

We would like to express our heartfelt gratitude to the Japan Society of Clinical Research (http://www.japanscr.org/) for their dedicated support.

\section{Funding}

The authors have no funding sources to declare.

\section{Availability of data and materials}

The datasets generated and/or analysed during the current study are not publicly available but are available from the corresponding author on reasonable request.

\section{Authors' contributions}

SA designed the study, and wrote the initial draft of the manuscript. MH contributed the analysis and interpretation of data, and assisted in the preparation of the manuscript. All other authors have contributed to data collection, interpretation, and critically reviewed the manuscript. The confirmed version of the manuscript was approved by all authors.

\section{Ethics approval and consent to participate}

The study protocol complied with the Helsinki Declaration standards and was approved by the Ethical Committee of St. Luke's International Hospital. The requirement for written informed consent was waived as this was a retrospective observational study.

Consent for publication

Not applicable.

\section{Competing interests}

The authors declare that they have no competing interests.

\section{Publisher's Note}

Springer Nature remains neutral with regard to jurisdictional claims in published maps and institutional affiliations.

\section{Author details}

'Department of Nephrology, St. Luke's International Hospital, Tokyo, Japan. ${ }^{2}$ Department of Nephrology, Graduate School of Medicine, Nippon Medical School, 1-1-5 Sendagi, Bunkyo-ku, Tokyo 113-8603, Japan. ${ }^{3}$ Department of Cardiovascular Medicine, Osaka City University Graduate School of Medicine, Osaka, Japan.

Received: 30 May 2017 Accepted: 29 September 2017

Published online: 18 October 2017

\section{References}

1. Adrogue HJ, Madias NE. Hyponatremia. N Engl J Med. 2000:342:1581-9.

2. Spasovski G, Vanholder R, Allolio B, Annane D, Ball S, Bichet D, et al. Clinical practice guideline on diagnosis and treatment of hyponatraemia. Eur J Endocrinol. 2014;170:G1-47.

3. Hoorn EJ, Lindemans J, Zietse R. Development of severe hyponatraemia in hospitalized patients: treatment-related risk factors and inadequate management. Nephrol Dial Transplant. 2006;21:70-6.

4. Buffington MA, Abreo K. Hyponatremia: a review. J Intensive Care Med. 2016;31:223-36.

5. Nagler EV, Vanmassenhove J, van der Veer SN, Nistor I, Van Biesen W, Webster AC, et al. Diagnosis and treatment of hyponatremia: a systematic review of clinical practice guidelines and consensus statements. BMC Med. 2014;12:1.

6. Hoorn EJ, Zietse R. Diagnosis and Treatment of Hyponatremia: Compilation of the Guidelines. J Am Soc Nephrol. 2017;28:1340-9.

7. Verbalis JG, Goldsmith SR, Greenberg A, Korzelius C, Schrier RW, Sterns RH, et al. Diagnosis, evaluation, and treatment of hyponatremia: expert panel recommendations. Am J Med. 2013;126(10 Suppl 1):S1-42.

8. Arieff Al. Hyponatremia, convulsions, respiratory arrest, and permanent brain damage after elective surgery in healthy women. $\mathrm{N}$ Engl J Med. 1986:314:1529-35.

9. Sterns RH, Riggs JE, Schochet SS Jr. Osmotic demyelination syndrome following correction of hyponatremia. N Engl J Med. 1986:314:1535-42.

10. Sood L, Sterns RH, Hix JK, Silver SM, Chen L. Hypertonic saline and desmopressin: a simple strategy for safe correction of severe hyponatremia. Am J Kidney Dis. 2013;61:571-8.

11. Rafat C, Schortgen F, Gaudry S, Bertrand F, Miguel-Montanes R, Labbe V, et al. Use of desmopressin acetate in severe hyponatremia in the intensive care unit. Clin J Am Soc Nephrol. 2014;9:229-37.

12. Perianayagam A, Sterns RH, Silver SM, Grieff M, Mayo R, Hix J, Kouides R. DDAVP is effective in preventing and reversing inadvertent overcorrection of hyponatremia. Clin J Am Soc Nephrol. 2008;3:331-6.

13. Gankam Kengne F, Soupart A, Pochet R, Brion JP, Decaux G. Re-induction of hyponatremia after rapid overcorrection of hyponatremia reduces mortality in rats. Kidney Int. 2009;76:614-21. 
14. Mohmand HK, Issa D, Ahmad Z, Cappuccio JD, Kouides RW, Sterns RH. Hypertonic saline for hyponatremia: risk of inadvertent overcorrection. Clin J Am Soc Nephrol. 2007;2:1110-7.

15. Sterns RH. Severe symptomatic hyponatremia: treatment and outcome. A study of 64 cases. Ann Intern Med. 1987;107:656-64.

16. Brunner JE, Redmond JM, Haggar AM, Kruger DF, Elias SB. Central pontine myelinolysis and pontine lesions after rapid correction of hyponatremia: a prospective magnetic resonance imaging study. Ann Neurol. 1990;27:61-6.

17. Sterns RH, Cappuccio JD, Silver SM, Cohen EP. Neurologic sequelae after treatment of severe hyponatremia: a multicenter perspective. J Am Soc Nephrol. 1994:4:1522-30.

18. Sterns RH, Thomas DJ, Herndon RM. Brain dehydration and neurologic deterioration after rapid correction of hyponatremia. Kidney Int. 1989;35:69-75

19. Geoghegan P, Harrison AM, Thongprayoon C, Kashyap R, Ahmed A, Dong Y, et al. Sodium correction practice and clinical outcomes in profound Hyponatremia. Mayo Clin Proc. 2015;90:1348-55.

20. Adams RD, Victor M, Mancall EL. Central pontine myelinolysis: a hitherto undescribed disease occurring in alcoholic and malnourished patients. AMA Arch Neurol Psychiatry. 1959;81:154-72.

21. Lohr JW. Osmotic demyelination syndrome following correction of hyponatremia: association with hypokalemia. Am J Med. 1994;96:408-13.

22. Lee EM, Kang JK, Yun SC, Kim KH, Kim SJ, Hwang KS, et al. Risk factors for central pontine and extrapontine myelinolysis following orthotopic liver transplantation. Eur Neurol. 2009;62:362-8.

23. Gankam-Kengne F, Ayers C, Khera A, de Lemos J, Maalouf NM. Mild hyponatremia is associated with an increased risk of death in an ambulatory setting. Kidney Int. 2013;83:700-6.

24. Holland-Bill L, Christiansen CF, Heide-Jorgensen U, Ulrichsen SP, Ring T, Jorgensen JO, Sorensen HT. Hyponatremia and mortality risk: a Danish cohort study of 279508 acutely hospitalized patients. Eur J Endocrinol. 2015;173:71-81.

25. Vu T, Wong R, Hamblin PS, Zajac J, Grossmann M. Patients presenting with severe hypotonic hyponatremia: etiological factors, assessment, and outcomes. Hosp Pract (1995). 2009:37:128-36.

26. Agrawal V, Agarwal M, Joshi SR, Ghosh AK. Hyponatremia and hypernatremia: disorders of water balance. J Assoc Physicians India. 2008;56:956-64.

27. Lin SH, Chau T, Wu CC, Yang SS. Osmotic demyelination syndrome after correction of chronic hyponatremia with normal saline. Am J Med Sci. 2002:323:259-62

28. Mozes B, Pines A, Werner D, Olchovsky D, Lieberman P, Frankl O. Thiazideinduced hyponatremia: an unusual neurologic course. South Med J. 1986;79:629-31.

29. Adrogue HJ, Madias NE. The challenge of hyponatremia. J Am Soc Nephrol. 2012;23:1140-8.

30. Hoorn EJ, Halperin ML, Zietse R. Diagnostic approach to a patient with hyponatraemia: traditional versus physiology-based options. QJM. 2005;98:529-40.

31. Fenske W, Maier SK, Blechschmidt A, Allolio B, Stork S. Utility and limitations of the traditional diagnostic approach to hyponatremia: a diagnostic study. Am J Med. 2010;123:652-7.

\section{Submit your next manuscript to BioMed Central and we will help you at every step:}

- We accept pre-submission inquiries

- Our selector tool helps you to find the most relevant journal

- We provide round the clock customer support

- Convenient online submission

- Thorough peer review

- Inclusion in PubMed and all major indexing services

- Maximum visibility for your research

Submit your manuscript at www.biomedcentral.com/submit 